\title{
CALCULATION OF EXPECTED SLIDING DISTANCE OF BREAKWATER CAISSON CONSIDERING VARIABILITY IN WAVE DIRECTION
}

\author{
SU YOUNG HONG \\ School of Civil, Urban, and Geosystem Engineering, Seoul National University, San 56-1, Shinlim-Dong, \\ Gwanak-Gu, Seoul151-742, Korea, E-mail: syshee1008@hanmail.net
}

\section{KYUNG-DUCK SUH ${ }^{1}$}

School of Civil, Urban, and Geosystem Engineering \& Research Institute of Marine Systems Engineering, Seoul National University, San 56-1, Shinlim-Dong, Gwanak-Gu, Seoul 151-742, Korea, E-mail: kdsuh@snu.ac.kr

\section{HYUCK-MIN KWEON}

Department of Civil Engineering, Kyongju University, San 42-1, Hyohyun-Dong, Kyongju-Si, Kyongsangbuk-Do 780-210, Korea, E-mail: hmkweon@kyongju.ac.kr

\footnotetext{
${ }^{1}$ Corresponding author, Temporal address until January, 2004: Department of Civil, Construction, and Environmental Engineering, Oregon State University, 202 Apperson Hall, Corvallis, Oregon 97331-2302, USA, Phone: +1-541-737-6891, Fax: +1-541-737-3052, Email: kdsuh@snu.ac.kr or kdsuh@engr.orst.edu
} 


\begin{abstract}
In this study, the reliability design method developed by Shimosako and Takahashi in 2000 for calculation of the expected sliding distance of the caisson of a vertical breakwater is extended to take into account the variability in wave direction. The effects of directional spreading and the variation of deepwater principal wave direction about its design value were found to be minor compared with those of the obliquity of the deepwater design principal wave direction from the shore-normal direction. Reducing the significant wave height at the design site by $6 \%$ to correct the effect of wave refraction when using Goda's model was found to be appropriate when the deepwater design principal wave direction was about 20 degrees. When we used the field data in a part of the east coast of Korea, taking the variability in wave direction into account reduced the expected sliding distance to about one third of that calculated without taking the variability in wave direction into account, and the required caisson width was reduced by about $10 \%$ at the maximum.
\end{abstract}

Keywords: Breakwater; caisson; expected sliding distance; reliability design; variability in wave direction; wave transformation model. 


\section{Introduction}

In the conventional design of the caisson of a vertical breakwater, the required sizes of the caisson are calculated from empirical formulas, with a certain margin of safety, so as to resist the design load related to a given return period. The conventional method is based on the force balance between the wave loads and the resistance of the caisson, and no movement of the caisson is allowed. Any small movement of the caisson is considered to be damage. However, even if the caisson moves, the breakwater can still perform its function, unless the movement is so great as to stop the serviceability of the breakwater. Therefore, if we allow a certain amount of movement of the caisson, a more economical design could be made.

In the conventional design, it is assumed that the lifetime of a breakwater is the same as the return period of the design wave. In this case, the probability of occurrence of wave heights greater than the design wave height during the lifetime of the breakwater is about 63 percent, which is larger than the probability for a wave height greater than the design height not to occur. For the breakwater located outside surf zone, the maximum wave height is usually taken to be 1.8 times the significant wave height, but a higher wave could appear especially when the storm duration is long. Moreover, errors are always involved in the computation of wave transformation and wave forces so that the computed values could happen to be on the safe side. Considering all these uncertainties, the conventional design uses a safety factor of 1.2 for sliding of a caisson, but its reasoning is not so clear. If the design conditions are different inside and outside surf zone, the degree of stability of the breakwater should not be the same, even if we use the same safety factor.

In order to cope with the problems mentioned above, reliability design methods or performance design methods have been developed, which take into account the uncertainties of various design parameters and allow a certain amount of damage during the lifetime of a breakwater. The reliability or performance design methods have been developed since the mid-1980s, especially in Europe and Japan. In Europe, van der Meer (1988) presented a probabilistic approach for the design of breakwater armor layer, and Burcharth (1991) introduced partial safety factors in the reliability design of rubble mound breakwaters. Recently Burcharth and Sørensen (1999) established partial safety factor systems for rubble mound breakwaters and vertical breakwaters by summarizing 
the results of the PIANC (Permanent International Association of Navigation Congresses) Working Groups. The European reliability design methods belong to what is called as Level 1 or Level 2 method. On the other hand, in Japan, Level 3 methods have been developed, in which the expected damage of breakwater armor blocks (Hanzawa et al., 1996) or the expected sliding distance of a breakwater caisson (Shimosako and Takahashi, 2000; Goda and Takagi, 2000; Takayama et al., 2000) during its lifetime is estimated. Monte Carlo simulations are used to take into account the uncertainties of various design factors.

Among the above-mentioned Japanese authors, Hanzawa et al. (1996) and Goda and Takagi (2000) used Goda's (1975) model to calculate the wave transformation from deep water to the design site, which includes wave attenuation due to random breaking. Unidirectional random waves normally incident to a straight coast with parallel depth contours were assumed so that no wave refraction was involved. Shimosako and Takahashi (2000) postulated wave transformation including refraction as well as shoaling and breaking, but they also used Goda's (1975) model in the actual computation (Shimosako, 2003). In real situations, directional random waves with variable principal wave directions will be incident to the shore. For more accurate computation of the wave heights at the design site, therefore, we should use more realistic wave transformation models taking into account the variability in wave direction. Recently Suh et al. (2002) extended the method of Hanzawa et al. (1996) to include the effect of the variability in wave direction in the calculation of the expected damage of breakwater armor blocks.

In the present study, by closely following Suh et al.'s (2002) approach, we extend the reliability design method of Shimosako and Takahashi (2000) for calculation of the expected sliding distance of the caisson of a vertical breakwater to take into account the variability in wave direction. The variability in wave direction includes directional spreading of random directional waves, obliquity of the design principal wave direction from the shore-normal direction, and its variation about the design value. To calculate the transformation of random directional waves over an arbitrary bathymetry including surf zone, we used Kweon et al.'s (1997) model, which was also used by Suh et al. (2002).

In the following section, the mathematical model to calculate the sliding distance of a caisson is described. In Sec. 3, the computational procedure for calculating the expected sliding distance of a caisson is explained. In Sec. 4, several computational examples are presented to compare the results of the present study with those of previous 
authors and to illustrate the importance of wave directionality. The major conclusions then follow.

\section{Computation of Sliding Distance}

The distance of caisson sliding is calculated with the model presented by Shimosako and Takahashi (2000), which is summarized below for the sake of completeness. Assuming that the caisson sliding is small enough to neglect the wave-making resistance force behind the caisson, the equation of motion describing caisson sliding is given by

$$
\left(\frac{W}{g}+M_{a}\right) \frac{d^{2} x_{G}}{d t^{2}}=P-F_{R}
$$

where $W$ is the caisson weight in the air, $g$ the gravity, $M_{a}$ the added mass $\left(=1.0855 \rho_{0} h^{\prime 2}\right), \rho_{0}$ the density of sea water, $h^{\prime}$ the water depth from bottom of caisson to design water level, $x_{G}$ the horizontal displacement of caisson, $P$ the horizontal wave force, $F_{R}$ the frictional resistance force $\left[=\mu\left(W^{\prime}-U\right)\right], \mu$ the friction coefficient, $W$ the caisson weight in water, and $U$ the uplift force. The sliding distance of the caisson can be calculated by numerically integrating the preceding equation twice with respect to time.

The horizontal force $P(t)$ is calculated by taking the larger value of a sinusoidal form $P_{1}(t)$ representing standing wave pressures and a triangular pulse $P_{2}(t)$ indicating impulsive pressures as shown in Figure 1, i.e.,

$$
\left.P(t)=\operatorname{ma} \underset{x}{ }(t), P_{2}(t)\right\}
$$

$P_{1}(t)$ and $P_{2}(t)$ are defined as follows:

$$
P_{1}(t)=\gamma_{P} P_{1 \max } \sin \frac{2 \pi t}{T}
$$




$$
\begin{aligned}
& P_{2}(t)= \begin{cases}\frac{2 t}{\tau_{0}} P_{2 \max }, & 0 \leq t \leq \frac{\tau_{0}}{2} \\
2\left(1-\frac{t}{\tau_{0}}\right) P_{2 \max }, & \frac{\tau_{0}}{2} \leq t \leq \tau_{0} \\
0, & t \geq \tau_{0}\end{cases} \\
& \gamma_{P}=1-\frac{\pi}{P_{1 \max } T} \int_{t_{1}}^{t_{2}}\left(P_{2}(t)-P_{1 \max } \sin \frac{2 \pi t}{T}\right) d t: \quad P_{2}(t)-P_{1 \max } \sin \frac{2 \pi t}{T} \geq 0
\end{aligned}
$$

where the time interval $\left[t_{1}, t_{2}\right]$ indicates the interval satisfying $P_{2}(t)-P_{1 \max } \sin (2 \pi t / T) \geq 0, P_{1 \max }$ the horizontal wave force calculated by the Goda (1974) pressure formula considering only the parameter $\alpha_{1}, P_{2 \max }$ the wave force calculated by using the Takahashi et al.'s (1994) parameter $\alpha^{*}$ in place of $\alpha_{2}$ in the Goda formula, $T$ the wave period, and $\tau_{0}$ the duration of the impulsive wave force. The parameter $\gamma_{P}$ is used to reduce the sinusoidally varying standing wave force by the amount increased due to the impulsive force.

Similarly, $U(t)$ is calculated as follows:

$$
\begin{gathered}
U(t)=\max \left\{U_{1}(t), U_{2}(t)\right\} \\
U_{1}(t)=\gamma_{U} U_{\max } \sin \frac{2 \pi t}{T}
\end{gathered}
$$




$$
\begin{aligned}
& U_{2}(t)= \begin{cases}\frac{2 t}{\tau_{0}} U_{\max }, & 0 \leq t \leq \frac{\tau_{0}}{2} \\
2\left(1-\frac{t}{\tau_{0}}\right) U_{\max }, & \frac{\tau_{0}}{2} \leq t \leq \tau_{0} \\
0, & t \geq \tau_{0}\end{cases} \\
& \gamma_{U}=1-\frac{\pi}{U_{\max } T} \int_{t_{1}}^{t_{2}}\left(U_{2}(t)-U_{\max } \sin \frac{2 \pi t}{T}\right) d t: \quad U_{2}(t)-U_{\max } \sin \frac{2 \pi t}{T} \geq 0
\end{aligned}
$$

where $U_{\max }$ denotes the uplift force calculated from the Goda formula.

The term $\tau_{0}$ is related to the wave period as follows:

$$
\tau_{0}=k \tau_{0 F}
$$

where the time $\tau_{0 F}$ and the constant $k$ are given by

$$
\tau_{0 F}=\left\{\begin{array}{lc}
\left(0.5-\frac{H}{8 h}\right) T, & 0 \leq \frac{H}{h} \leq 0.8 \\
0.4 T, & \frac{H}{h}>0.8
\end{array}\right.
$$

and

$$
k=\left(\frac{1}{\left(\alpha^{*}\right)^{0.3}+1}\right)^{2}
$$

respectively. Here $H$ is the wave height, and $h$ the water depth.

\section{Procedure for Computation of Expected Sliding Distance}


In this section, the procedure for computing the expected sliding distance is explained in conjunction with the computational flow chart sketched in Figure 2. In general, the sliding of a breakwater caisson is caused by large waves comparable to the design waves. Therefore, the annual maximum wave height is considered sufficient to be incorporated into the calculation. The annual maximum offshore significant wave height $H_{0 e}$ is randomly sampled from the extreme wave height distribution (Weibull distribution in this study), and the peak of storm waves is assumed to continue for 2 hours. This wave height is further given a stochastic variation with the normal distribution having a mean $\mu_{H_{0}}$ and standard deviation $\sigma_{H_{0}}$. This variation represents the uncertainty in the estimate of the extreme distribution function owing to the limited sample size of extreme wave data or the inaccuracy in wave hindcasts. The mean and standard deviation are assumed to have the following relations with $H_{0 e}$ (Takayama and Ikeda, 1994):

$$
\mu_{H_{0}}=\left(1+\alpha_{H_{0}}\right) H_{0 e}, \quad \sigma_{H_{0}}=\gamma_{H_{0}} H_{0 e}
$$

where $\alpha_{H_{0}}$ and $\gamma_{H_{0}}$ denote the bias and deviation coefficient, respectively. The sample offshore wave height $H_{0 c}$ to be employed in the calculation is then determined by a normalized random number based on Eq. (13). The corresponding significant wave period is determined to yield a constant wave steepness ( 0.03 in this study) in the offshore area:

$$
T_{s e}=\sqrt{\frac{2 \pi H_{0 c}}{0.03 g}}
$$

This wave period may also contain uncertainty and thus is given a stochastic variation with the normal distribution having a mean $\mu_{T_{s}}$ and standard deviation $\sigma_{T_{s}}$. The mean and standard deviation are assumed to have the following relations with $T_{s e}$ : 


$$
\mu_{T_{s}}=\left(1+\alpha_{T_{s}}\right) T_{s e}, \quad \sigma_{T_{s}}=\gamma_{T_{s}} T_{s e}
$$

where $\alpha_{T_{s}}$ and $\gamma_{T_{s}}$ denote the bias and deviation coefficient, respectively. The sample significant wave period $T_{S C}$ to be employed in the calculation is then determined by a normalized random number based on Eq. (15).

Offshore random directional waves with the directional spreading parameter $s_{\max }$ are assumed to be incident with the principal wave direction $\left(\alpha_{P}\right)_{0}$ counterclockwise with respect to the shore-normal direction. The principal wave direction is assumed to have a stochastic variation with the normal distribution having a mean being the same as the design principal wave direction $\left(\alpha_{P}\right)_{0 D}$ and a standard deviation $\sigma\left(\alpha_{p}\right)_{0}$. Unidirectional random waves normally incident to the shore are simulated by setting $s_{\max }=\infty, \sigma\left(\alpha_{p}\right)_{0}=0$, and $\left(\alpha_{p}\right)_{0 D}=0$. The offshore directional wave spectrum was expressed as the product of the Bretschneider-Mitsuyasu frequency spectrum and the Mitsuyasu-type directional spreading function (Goda, 2000, Section 2.3.2).

With the tidal range of $\Delta \eta$, tide level $\eta_{t}$ was assumed to vary sinusoidally between $\operatorname{LWL}\left(\eta_{t}=0\right)$ and $\operatorname{HWL}\left(\eta_{t}=\Delta \eta\right)$. The effect of storm surge was taken into account by adding $10 \%$ of the deepwater wave height to the tide level.

Once the offshore wave height, wave period, and tide level are determined, the significant wave height at the location of the breakwater should be calculated. In order to take into account the effect of wave direction on wave transformation, we use Kweon $e t$ al.'s (1997) wave transformation model in the present study. The significant wave height at the design site $H_{s e}$, calculated by the wave transformation model, is also assumed to have computational uncertainty, and thus is given stochastic variation with the normal distribution as with the offshore wave height. The mean $\mu_{H_{s}}$ and the standard deviation $\sigma_{H_{s}}$ are assumed to have the following relations with $H_{s e}$ : 


$$
\mu_{H_{s}}=\left(1+\alpha_{H_{s}}\right) H_{s e} \quad, \quad \sigma_{H_{s}}=\gamma_{H_{s}} H_{s e}
$$

where $\alpha_{H_{s}}$ and $\gamma_{H_{s}}$ denote the bias and deviation coefficient, respectively. The sample wave height at the design site $H_{s c}$ is determined by a normalized random number based on Eq. (16). The Kweon et al.'s (1997) model computes the mean wave direction as well as the wave height at the design site. The computed wave direction is used as an input parameter in the calculation of wave pressure using the Goda formula.

Once the significant wave height at the location of the breakwater is calculated, the heights of the individual waves during the storm are randomly sampled by assuming the Rayleigh distribution. An individual wave height greater than the breaking wave height was reduced to the breaking wave height using the formula in Goda (2000, p. 81). The periods of the individual waves are given stochastic variation with the normal distribution as with the significant wave period. The mean $\mu_{T}$ and the standard deviation $\sigma_{T}$ are assumed to have the following relations with $T_{S C}$ :

$$
\mu_{T}=\left(1+\alpha_{T}\right) T_{s c}, \quad \sigma_{T}=\gamma_{T} T_{s c}
$$

where $\alpha_{T}$ and $\gamma_{T}$ denote the bias and deviation coefficient, respectively.

Theoretically, the total sliding distance during the lifetime of a breakwater should be calculated by summing the sliding distances due to all the high waves during the lifetime. In the present study, however, we assume that the waves high enough to make a caisson slide appear once a year so that the annual maximum wave height is sufficient to be incorporated into the calculation. Therefore, the total sliding distance is obtained by repeating the calculation for the number of years of the breakwater lifetime (usually 50 years). The process of one lifetime cycle is shown in Figure 2. This process is repeated a large number of times, and the expected sliding distance is obtained by taking the average of the total sliding distance during each lifetime cycle. In order to take into account the stochastic variation of various design parameters such as wave height, wave period, water level, wave force, and friction coefficient, the Monte-Carlo simulation 
method was used. Table 1 lists the design parameters employed in the present study and their bias and deviation coefficient.

\section{Illustrative Examples}

In this section, we present several computational examples to compare our results with those of previous authors and to illustrate the importance of wave directionality. We consider only a plane beach, which is simple but sufficient to illustrate the influence of wave directionality. The common computational conditions are given below.

The Weibull distribution function with the shape parameter $k=2.0$, scale parameter $A=2.23$, and location parameter $B=4.78$ was used as the extreme distribution of the offshore wave height, which gave a design deepwater wave height with a return period of 50 years to be $9.2 \mathrm{~m}$. The deepwater wave steepness was assumed to be constant at 0.03 so that the corresponding design wave period was $14.0 \mathrm{~s}$. The bias and deviation coefficient of various design parameters are given in Table 1, which are basically the same as those used by Shimosako and Takahashi (2000). In the surf zone, the deviation coefficient of wave force of obliquely incident waves may be smaller than that of normal incidence, because the impulsive breaking wave pressure with larger deviation than standing wave pressure occurs only when the wave direction is almost normal to the breakwater. Unfortunately, however, there is not enough experimental data about this. Therefore, we used the same value as that used by Shimosako and Takahashi (2000) regardless of wave direction, because their results are later compared with the present model results. A tidal range of $2.0 \mathrm{~m}$ was assumed, and water depths from 10 to $30 \mathrm{~m}$ at LWL at an interval of $2 \mathrm{~m}$ were examined. Seabed slopes of 1/50 and 1/20 were used. The design wave height at each water depth was determined by computing the wave heights corresponding to $H_{0}=9.2 \mathrm{~m}$ while changing the water level from LWL to HWL and taking the largest wave height. The total number of simulations for the calculation of expected sliding distance was chosen to be 5000 based on Shimosako and Takahashi (2000), who have shown that a stable statistical result can be obtained by doing so.

The breakwater is assumed to be installed parallel to the shoreline. The design significant wave heights, maximum wave heights and caisson widths at different water 
depths are given in Table 2. These values are also plotted in Figure 3 for later use. A constant mound berm width of $8.0 \mathrm{~m}$ was used regardless of water depth. The crest elevation of the caisson was taken to be 0.6 times the design significant wave height at the location of the breakwater. The water depth on the rubble mound, $d$, was taken to be $0.65 \mathrm{~h}$. The height from the bottom of the caisson to the top of the rubble mound was assumed to be $2.0 \mathrm{~m}$ so that $h^{\prime}=d+2.0 \mathrm{~m}$ was used. The width of the caisson was calculated by the Goda formula with the safety factor of 1.2. In the following, the expected sliding distance was calculated for the caisson width given in Table 2 in each water depth.

\subsection{Unidirectional random waves normally incident to plane beach}

Shimosako and Takahashi (2000) computed the expected sliding distance of the caisson of a vertical breakwater exposed to unidirectional random waves normally incident to a plane beach using Goda's (1975) model. On the other hand, Kweon et al. (1997) simulated the unidirectional random waves on a plane beach by setting the directional spreading parameter $s_{\max }$ to be 1000 in their three-dimensional random breaking wave model, showing that their results were in reasonably good agreement with Goda's. Herein we used Kweon et al.'s model to compute the wave transformation, and compared the calculated expected sliding distance of the caisson with Shimosako and Takahashi's results. It was expected that these two results would not show great difference because the wave models used gave similar results. The parameters expressing the uncertainties in the computation of wave transformation were $\alpha_{H_{s}}=0.0$ and $\gamma_{H_{s}}=0.1$ as with Shimosako and Takahashi.

Figure 4 compares the expected sliding distance at different water depths between the present model and the Shimosako and Takahashi's (2000) model. A small difference is observed for water depths greater than $20 \mathrm{~m}$ because of the difference between the two wave transformation models used, but the overall trend with respect to the water depth is quite similar. Note that a safety factor of 1.0 was used in all the computation of caisson sliding distance hereafter including Figure 4.

\subsection{Influence of variability in wave direction}


The primary purpose of the present study is to examine the influence of the variability in wave direction upon the computation of the expected sliding distance of a caisson, which was not included in Goda's (1975) model. For this purpose, we carried out the computation for the eight cases listed in Table 3.

Case 1 is for unidirectional waves normally incident to the beach as in Goda's (1975) model. Case 2 includes the effect of directional spreading. The spreading parameter $s_{\max }$ equal to 20 was used, which corresponds to the deepwater wave steepness of 0.03 (Goda, 2000, p. 35). Case 3 is for unidirectional waves incident at $20^{\circ}$ with respect to the shore-normal direction, including only the effect of wave refraction. Case 4 examines the effect of the variation of the principal wave direction. $\left(\alpha_{p}\right)_{0 D}=0^{\circ}$ and $\sigma_{\left(\alpha_{p}\right)_{0}}=15^{\circ}$ were used. For Cases 1 to $4, \alpha_{H_{s}}=-0.06$ and $\gamma_{H_{s}}=0.1$ were used. Cases 2 to 4 , however, included a fraction of the effects of refraction and directional spreading that were ignored in Goda's (1975) model. Therefore, the bias must be smaller than -0.06 , e.g., -0.04 . However, how small was uncertain, so the value of -0.06 was used without change. Cases 5 to 8 included all of the variability in wave direction partly considered in Cases 2 to 4 . To examine the influence of the principal wave direction, the expected sliding distance was calculated in Cases 5 to 7 with the deepwater principal wave direction of 10,20 , and 30 degrees, respectively. Case 8 represented the typical conditions between Uljin and Pohang in the east coast of Korea as given by Suh et al. (2002). In Cases 5 to 8, all of the variability in wave direction was included, so no bias was assumed in the computation of wave transformation, i.e., $\alpha_{H_{s}}=0.0$ was used.

However, the computational error must still exist, so $\gamma_{H_{s}}=0.1$ was kept the same.

Figure 5 shows a comparison of the expected sliding distance at different water depths between Case 1 and 2. In Case 2 where the effect of directional spreading is included, the wave height at the location of the breakwater becomes smaller compared with that of the unidirectional waves in Case 1. Therefore, the expected sliding distance in Case 2 is smaller than in Case 1. The difference of expected sliding distance between the two cases becomes smaller as water depth decreases, because the effect of directional 
spreading disappears as the waves propagate toward the shore.

Figure 6 shows a comparison between Case 1 and 3. The height of obliquely incident waves is smaller than that of normally incident waves owing to wave refraction. Thus, the expected sliding distance in Case 3 is smaller than in Case 1. Figure 7 shows a comparison between Case 1 and 4. Again due to the effect of wave refraction, the expected sliding distance in Case 4 is computed to be smaller than in Case 1. Figure 6 and 7 show that the effect of wave refraction diminishes with decreasing water depth. This is probably because, in shallow water, the maximum wave height is restricted by the water depth so that the wave thrust has an upper limit.

Comparison of Figures 5 to 7 shows that the effect of directional spreading is almost same as that of variation of principal wave direction, but the effect of wave refraction is greater than these two effects even for a relatively small deepwater wave incident angle of 20 degrees.

Figures 8, 9 and 10 show comparisons between Case 1 and Cases 5, 6 and 7, respectively, which examine the influence of the principal wave direction on the expected sliding distance when all the variability in wave direction is taken into account. In Cases 5, 6 and 7, the deepwater principal wave direction was 10, 20 and 30 degrees, respectively. As seen in Figure 8, when the deepwater principal wave direction was 10 degrees, the expected sliding distance calculated with the variability in wave direction taken into account is greater than that calculated without taking the variability into account. On the contrary, when the principal wave direction was 30 degrees, the opposite occurs as shown in Figure 10. On the other hand, the expected sliding distances calculated with and without taking the variability in wave direction into account almost coincide each other when the principal wave direction was 20 degrees, as shown in Figure 9. From the results given in Figures 8 to 10 , we can say that the bias $\alpha_{H_{s}}=-0.06$ employed to take into account the variability in wave direction is suitable when the deepwater design principal wave direction is about $20^{\circ}$. Note that the bias $\alpha_{H_{s}}=-0.06$ was used in Case 1 but $\alpha_{H_{s}}=0.0$ in Cases 5 to 7 . A value smaller than -0.06 in magnitude (e.g., -0.04 ) should be used when $\left(\alpha_{p}\right)_{0 D}$ is smaller than $20^{\circ}$, or vice versa. More computations may be needed for different wave conditions and 
seabed slopes to obtain a more reliable relation between $\left(\alpha_{p}\right)_{0 D}$ and $\alpha_{H_{s}}$.

Figure 11 shows a comparison between Case 1 and 8 . Because the deepwater principal wave direction is very large at $48^{\circ}$ in Case 8 , the significant wave height at the location of the breakwater is calculated to be very small due to the effect of severe wave refraction. Therefore, the expected sliding distance in Case 8 is very small compared with that in Case 1. The difference from Case 1 is prominent even in smaller water depths, which is seen a little in Figure 10 but is hardly seen in Figures 8 and 9, where the deepwater principal wave direction is relatively small and so is wave refraction.

When the seabed slope is $1 / 20$, the expected sliding distances are very small in water depths smaller than about $16 \mathrm{~m}$ for all the cases shown in Figures 4 to 11. As shown in Figure 3, the caisson width is quite large in these water depths of $1 / 20$ beach slope though $H_{\max }$ decreases with decreasing water depth because of wave breaking. It seems that inside the surf zone of a steep beach the conventional design method is too conservative in the viewpoint of expected sliding distance. Another feature seen in Figures 4 to 11 is that the expected sliding distance of $1 / 20$ slope is smaller than that of $1 / 50$ slope in water depths smaller than about $18 \mathrm{~m}$, the reverse happens in water depths between 18 and $26 \mathrm{~m}$, and the reverse happens again in greater water depths. This also seems to be related to the caisson widths shown in Figure 3. On the beach of 1/20 slope the caisson widths are relatively large in smaller water depths, while on the 1/50 slope beach relatively large caisson widths are needed in the middle water depths of 16 to $22 \mathrm{~m}$. Again it seems that the conventional design method is conservative so that a smaller expected sliding distance is calculated when the caisson width is relatively large. However, the influence of seabed slope is not clear and further investigation is needed.

Figure 12 shows the ratio of $B_{30}$, the caisson width designed for the expected sliding distance to be $30 \mathrm{~cm}$, to $B_{d}$, the caisson width designed with the conventional method, as a function of water depth, for Cases 1 and 8 . In this figure, the relative caisson width $B_{30} / B_{d}$ smaller than 1.0 means that the present design method is more economical than the conventional one, or vice versa. Even in Case 1 where the variability in wave direction was not taken into account, the present design method is more economical than the conventional one in water depths smaller than about $25 \mathrm{~m}$ (or 
$H_{0 D} / h \geq 0.37$ ), while the reverse is true in deeper water. However, since $H_{0 D} / h$ is larger than 0.37 for most ordinary design conditions, the present design method generally gives a more economical cross section. In Case 8 where the variability in wave direction was taken into account, $B_{30} / B_{d}$ is smaller than 1.0 , indicating that the present design method is more economical than the conventional one in all the water depths examined. Other cases show similar trends except that the difference from Case 1 is different for each case. For example, $B_{30} / B_{d}$ is almost same between Case 1 and 6 as shown in Figure 13. Note that the expected sliding distance was almost same between these two cases (see Figure 9).

\section{Conclusions}

In this study, the deformation-based reliability design method developed by Shimosako and Takahashi (2000) for calculating the expected sliding distance of the caisson of a vertical breakwater was extended to take into account the variability in wave direction. On the whole, the effect of directional spreading or the variation of the deepwater principal wave direction about its design value is not so significant, but the effect of the obliquity of the design principal wave direction from the shore-normal direction is relatively important so that the expected sliding distance tends to decrease with increasing obliquity of principal wave direction. Especially in the case where the field data in the east coast of Korea were used, the expected sliding distance calculated with the variability in wave direction taken into account was reduced to about one third of that calculated without taking the variability into account.

Reducing the significant wave height at the design site by $6 \%$ to correct the effect of wave refraction neglected by assuming unidirectional waves normally incident to a coast with straight and parallel depth contours seems to be appropriate for the deepwater design principal wave direction of about 20 degrees. A smaller or larger reduction should be used for the deepwater principal wave direction smaller or larger, respectively, than 20 degrees. It may also be possible to propose a relationship between the deepwater design principal wave direction and the bias of wave transformation through more computation in the future.

If we design the caisson with the allowable expected sliding distance of $30 \mathrm{~cm}$, in 
water depths smaller than about $25 \mathrm{~m}$, even without taking the variability in wave direction into account, the width of the caisson could be reduced up to 30 percent compared with the conventional design. When we used the field data in the east coast of Korea and took into account the variability in wave direction, the required caisson width was reduced by about 10 percent at the maximum, and a smaller caisson width was required than the conventional design in the whole range of water depth (10 to $30 \mathrm{~m}$ ).

\section{Acknowledgement}

This work was supported by the Brain Korea 21 Project.

\section{References}

Burcharth, H. F. (1991). "Introduction of partial coefficient in the design of rubble mound breakwaters." Proc. Conf. on Coastal Structures and Breakwaters, Inst. of Civil Engrs., London, pp. 543-565.

Burcharth, H. F. and Sørensen, J. D. (1999). "The PIANC safety factor system for breakwaters." Proc. Int. Conf. Coastal Structures '99, A. A. Balkema, Spain, pp. 1125-1144.

Goda, Y. (1974). "A new method of wave pressure calculation for the design of composite breakwater." Proc. 14th Int. Conf. on Coastal Engrg., American Soc. of Civil Engrs., Copenhagen, pp. 1702-1720.

Goda, Y. (1975). "Irregular wave deformation in the surf zone.” Coastal Engrg., Japan, 18 , pp. 13-26.

Goda, Y. (2000). Random Seas and Design of Maritime Structures, 2nd edn., World Scientific, Singapore.

Goda, Y. and Takagi, H. (2000). "A reliability design method of caisson breakwaters with optimal wave heights." Coastal Engrg. J., 42(4), pp. 357-387.

Hanzawa, M., Sato, H., Takahashi, S., Shimosako, K., Takayama, T. and Tanimoto, K. (1996). "New stability formula for wave-dissipating concrete blocks covering horizontally composite breakwaters." Proc. 25th Int. Conf. on Coastal Engrg., 
American Soc. of Civil Engrs., Orlando, pp. 1665-1678.

Kweon, H.-M., Sato, K. and Goda, Y. (1997). "A 3-D random breaking model for directional spectral waves." Proc. 3rd Int. Symp. on Ocean Wave Measurement and Analysis, American Soc. of Civil Engrs., Norfolk, pp. 416-430.

Shimosako, K. (2003). Personal communication.

Shimosako, K. and Takahashi, S. (2000). "Application of deformation-based reliability design for coastal structures." Proc. Int. Conf. Coastal Structures '99, A. A. Balkema, Spain, pp. 363-371.

Suh, K. D., Kweon, H.-M. and Yoon, H. D. (2002). "Reliability design of breakwater armor blocks considering wave direction in computation of wave transformation." Coastal Engrg. J., 44(4), pp. 321-341.

Takahashi, S., Tanimoto, K. and Shimosako, K. (1994). "A proposal of impulsive pressure coefficient for the design of composite breakwaters." Proc. Int. Conf. HydroTechnical Engrg. for Port and Harbour Constuction, Yokosuka, Japan, pp. 489-504.

Takayama, T. and Ikeda, N. (1994). "Estimation of encounter probability of sliding for probabilistic design of breakwater." Proc. Wave Barriers in Deepwaters, Port and Harbour Research Institute, Yokosuka, pp. 438-457.

Takayama, T., Ikesue, S.-I. and Shimosako, K.-I. (2000). "Effect of directional occurrence distribution of extreme waves on composite breakwater reliability in sliding failure." Proc. 27th Int. Conf. on Coastal Engrg., American Soc. of Civil Engrs., Sydney, pp. 1738-1750.

van der Meer, J. W. (1988). "Deterministic and probabilistic design of breakwater armor layers." J. Waterway, Port, Coastal and Ocean Engrg., American Soc. of Civil Engrs., 114, pp. 66-80. 
Table 1. Estimation errors of design parameters.

\begin{tabular}{|c|c|c|c|}
\hline Design parameters & Bias & $\begin{array}{l}\text { Deviation } \\
\text { coefficient }\end{array}$ & Remarks \\
\hline $\begin{array}{l}\text { Offshore wave } \\
\text { height }\end{array}$ & 0.0 & 0.1 & \\
\hline Storm surge & 0.0 & 0.1 & $\begin{array}{c}\text { Standard is } 10 \% \text { of offshore } \\
\text { wave height }\end{array}$ \\
\hline $\begin{array}{c}\text { Wave } \\
\text { transformation }\end{array}$ & -0.06 or 0.0 & 0.1 & \\
\hline $\begin{array}{l}\text { Significant wave } \\
\text { period }\end{array}$ & 0.0 & 0.1 & \\
\hline $\begin{array}{c}\text { Period of } \\
\text { individual waves }\end{array}$ & 0.0 & 0.1 & \\
\hline Wave force & 0.0 & 0.1 & Goda formula considering $\alpha^{*}$ \\
\hline Friction coefficient & 0.0 & 0.1 & Standard is $\mu=0.6$ \\
\hline
\end{tabular}


Table 2. Design wave heights and widths of caisson in different water depths.

\begin{tabular}{cccccc}
\hline \multicolumn{7}{c}{ Sea Bed Slope $1 / 20$} \\
\hline$h(\mathrm{~m})$ & 10 & 12 & 14 & 16 & 18 \\
$H_{S}(\mathrm{~m})$ & 8.72 & 9.42 & 9.94 & 9.71 & 9.48 \\
$H_{\max }(\mathrm{m})$ & 12.85 & 14.20 & 15.23 & 15.77 & 15.88 \\
$B \quad(\mathrm{~m})$ & 26.30 & 27.40 & 27.59 & 27.03 & 25.50 \\
\hline \multicolumn{7}{c}{} & \multicolumn{7}{c}{ Sea Bed Slope $1 / 20$} & & \\
\hline 20 & 22 & 24 & 26 & 28 & 30 \\
9.28 & 9.15 & 9.05 & 8.98 & 8.92 & 8.87 \\
15.51 & 15.37 & 15.26 & 15.16 & 15.08 & 15.01 \\
23.10 & 21.62 & 20.40 & 19.38 & 18.52 & 17.77 \\
\hline
\end{tabular}

\begin{tabular}{cccccc}
\hline \multicolumn{7}{c}{ Sea Bed Slope $1 / 50$} \\
\hline$h(\mathrm{~m})$ & 10 & 12 & 14 & 16 & 18 \\
$H_{S}(\mathrm{~m})$ & 7.32 & 8.30 & 9.08 & 9.56 & 9.46 \\
$H_{\max }(\mathrm{m})$ & 10.39 & 11.69 & 12.88 & 13.94 & 14.74 \\
$B \quad(\mathrm{~m})$ & 18.29 & 19.55 & 20.64 & 21.51 & 22.17 \\
\hline \multicolumn{7}{c}{} & \multicolumn{7}{c}{ Sea Bed Slope $1 / 50$} & & \\
\hline 20 & 22 & 24 & 26 & 28 & 30 \\
9.28 & 9.15 & 9.05 & 8.98 & 8.92 & 8.87 \\
15.22 & 15.30 & 15.16 & 15.05 & 14.96 & 14.88 \\
22.11 & 21.26 & 20.04 & 19.05 & 18.21 & 17.48 \\
\hline
\end{tabular}


Table 3. Test conditions.

\begin{tabular}{ccccc}
\hline Case No. & $s_{\max }$ & $\left(\alpha_{p}\right)_{0 D}($ deg. $)$ & $\sigma_{\left(\alpha_{p}\right)_{0}}($ deg. $)$ & $\alpha_{H_{s}}$ \\
\hline 1 & 1000 & 0 & 0 & -0.06 \\
2 & 20 & 0 & 0 & -0.06 \\
3 & 1000 & 20 & 0 & -0.06 \\
4 & 1000 & 0 & 15 & -0.06 \\
5 & 20 & 10 & 15 & 0 \\
6 & 20 & 20 & 15 & 0 \\
7 & 20 & 30 & 15 & 0 \\
8 & 20 & 48 & 17 & 0 \\
\hline
\end{tabular}




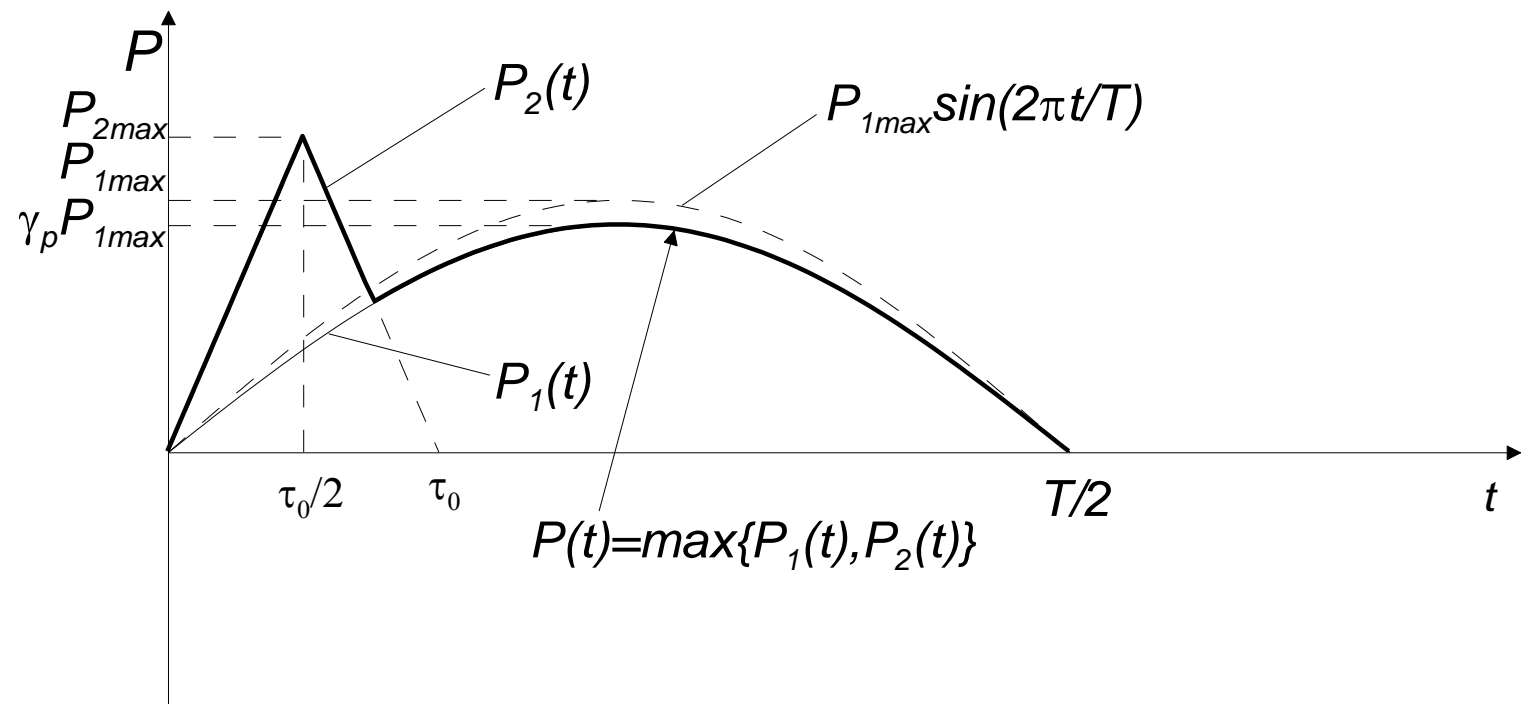

Figure 1. Wave force profile for calculation of sliding distance. 


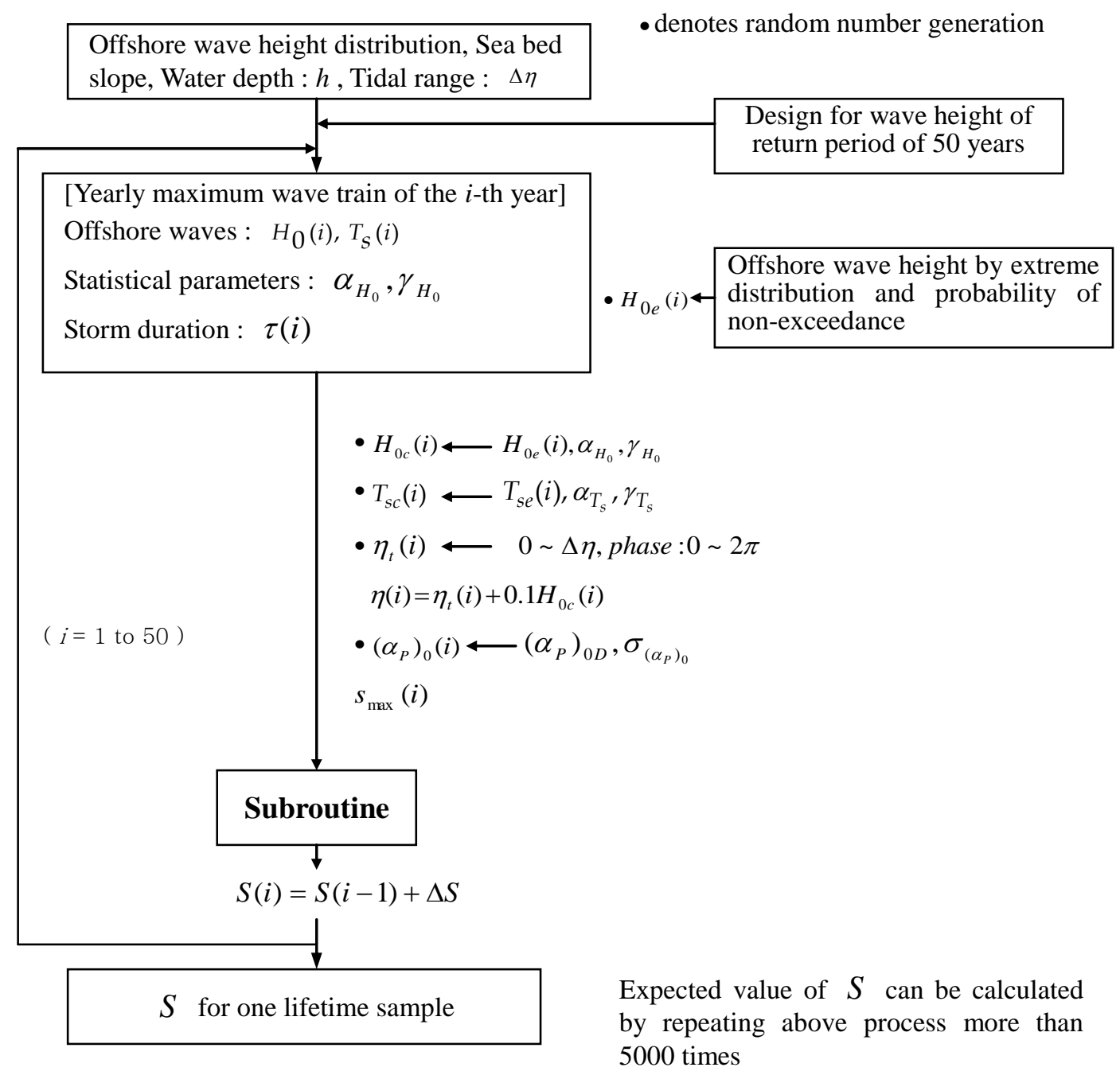

(a) Computational flow

Figue 2. Flow chart for computation of total sliding distance within one lifetime. 


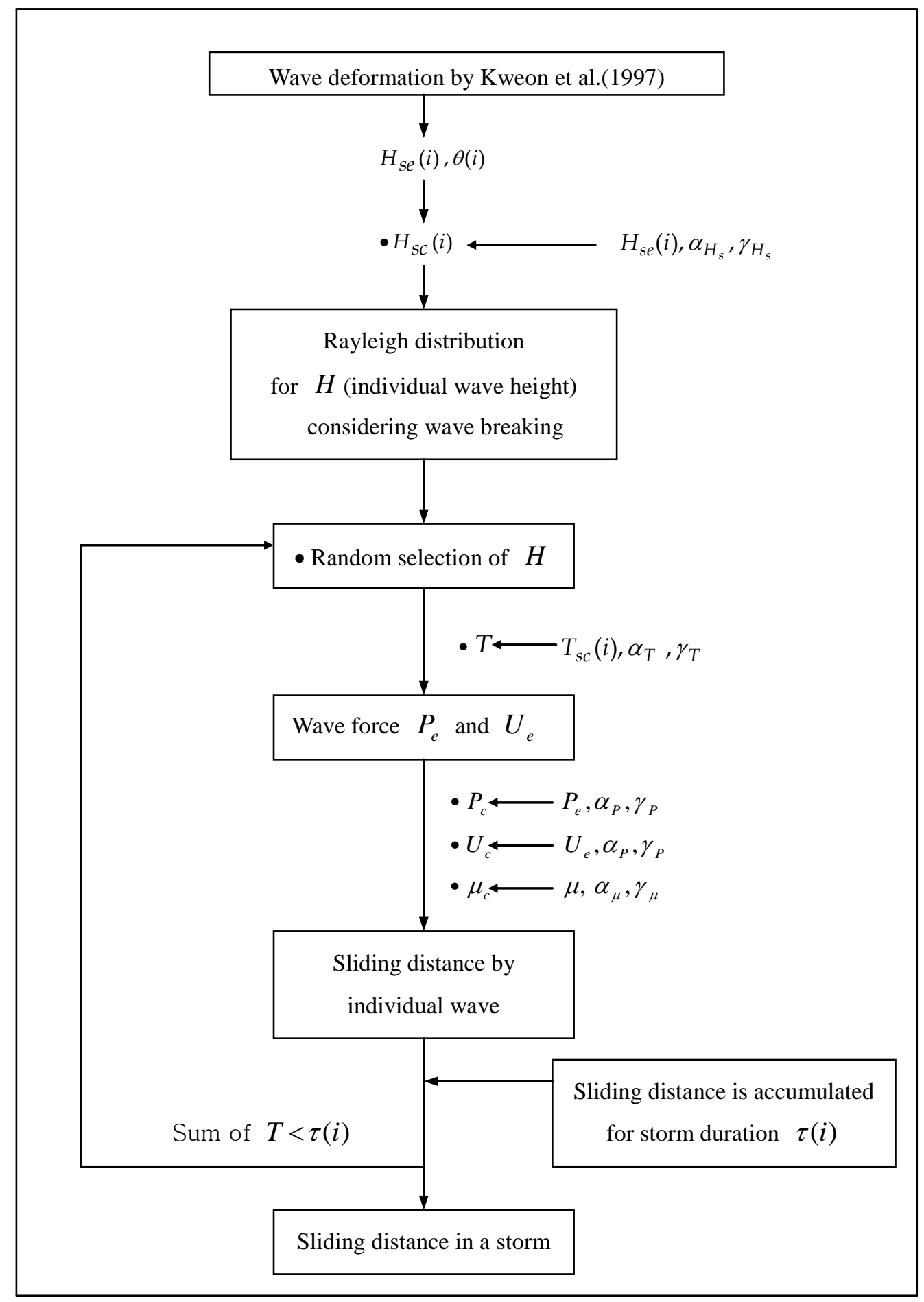

(b) Subroutine

Figure 2. Continued. 


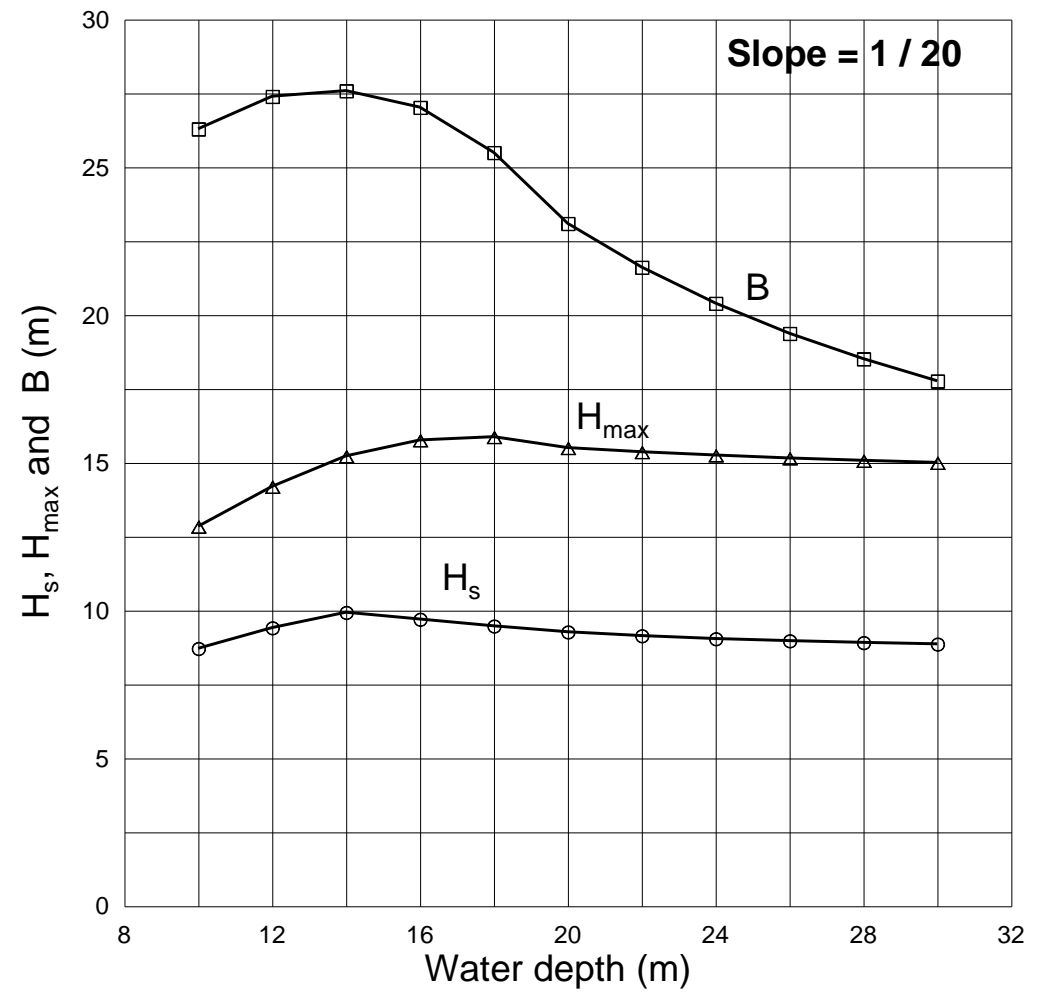

Figure 3. Design wave heights and widths of caisson in different water depths. 


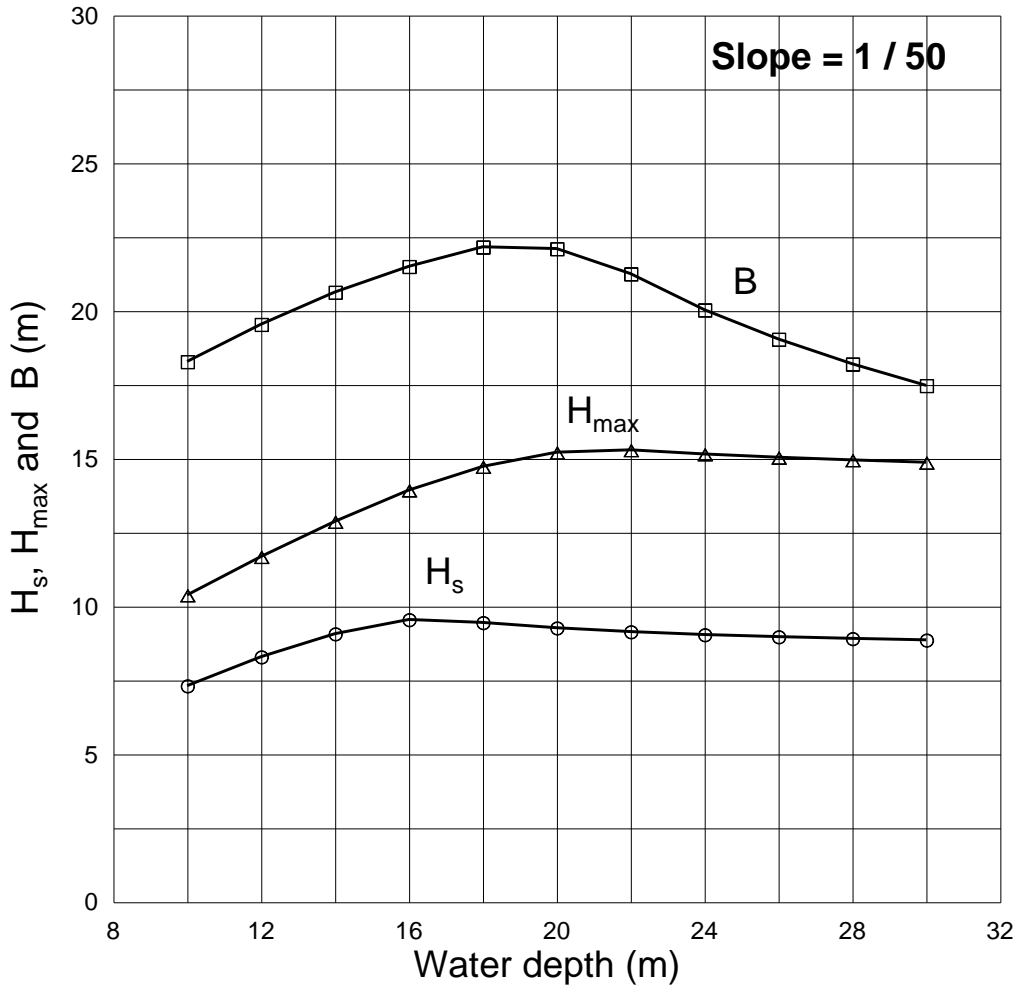

Figure 3. Continued. 


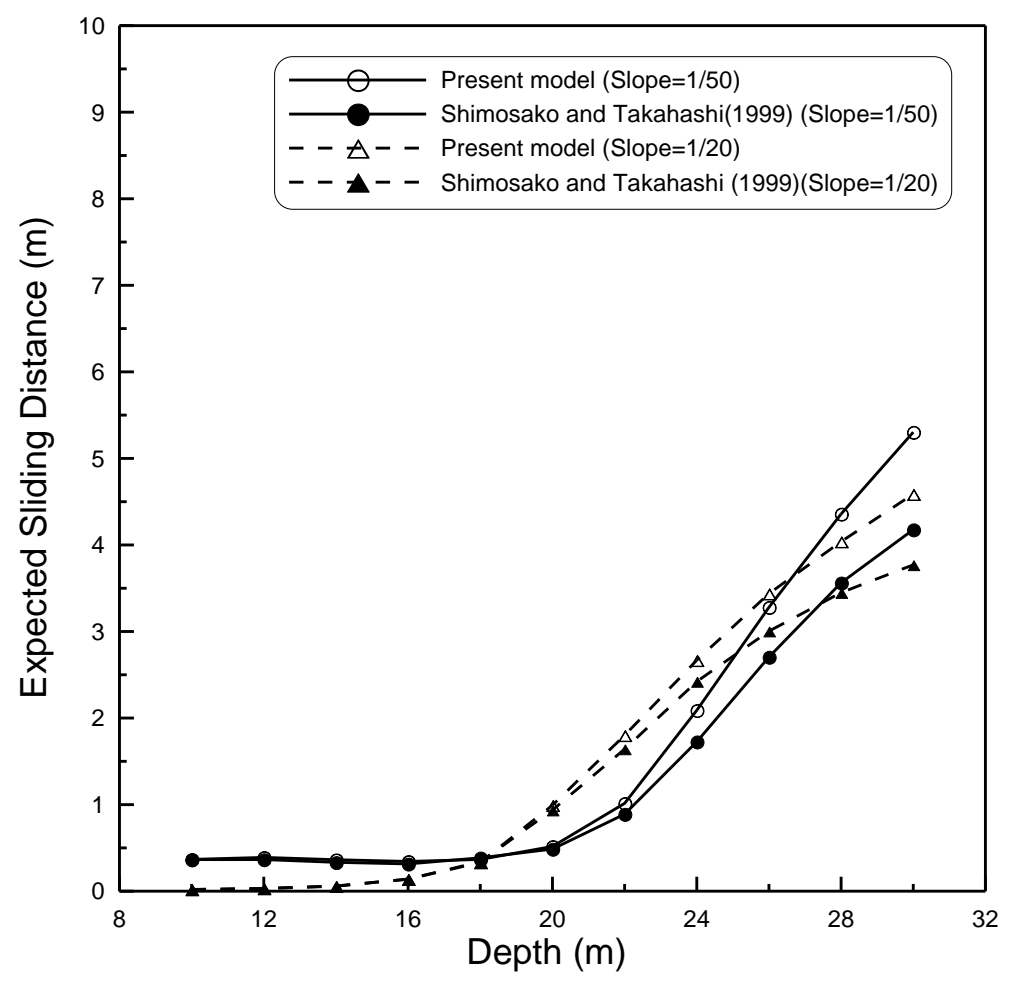

Figure 4. Comparison of expected sliding distance between present model and Shimosako and Takahashi's (2000) model. 


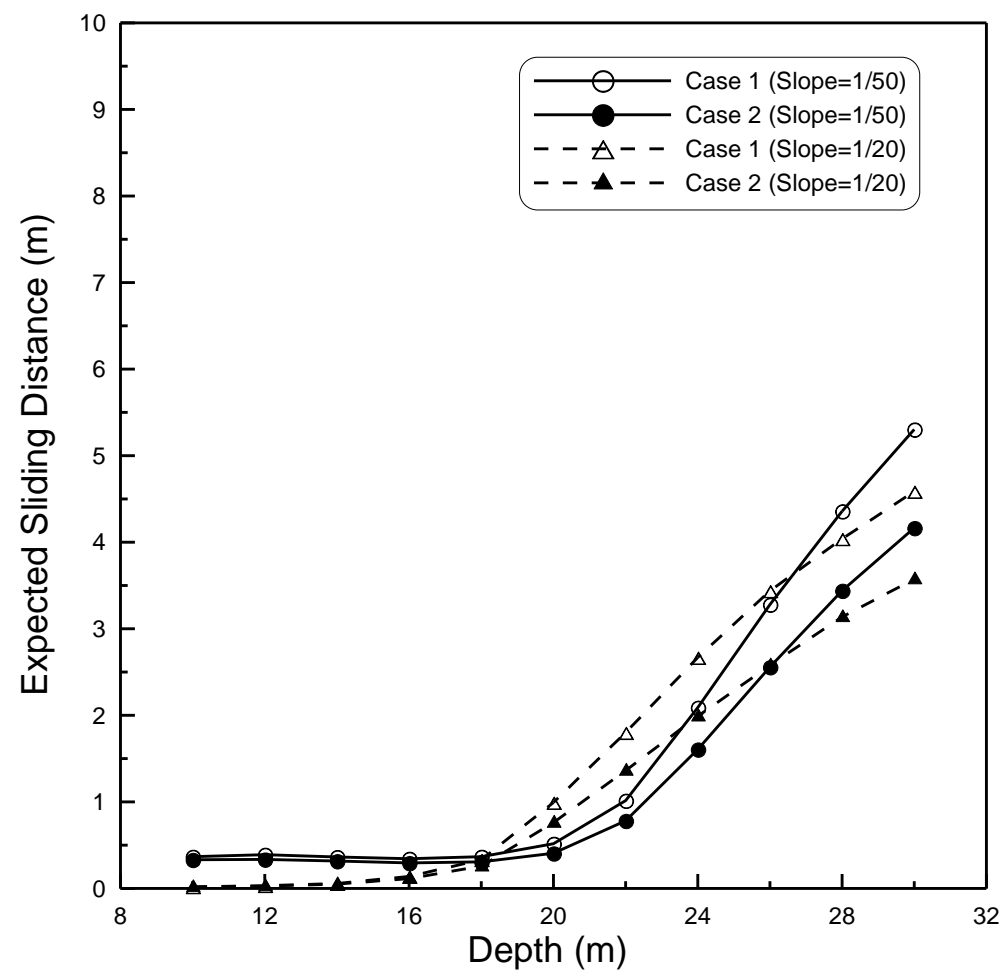

Figure 5. Change of expected sliding distance due to effect of directional spreading. 


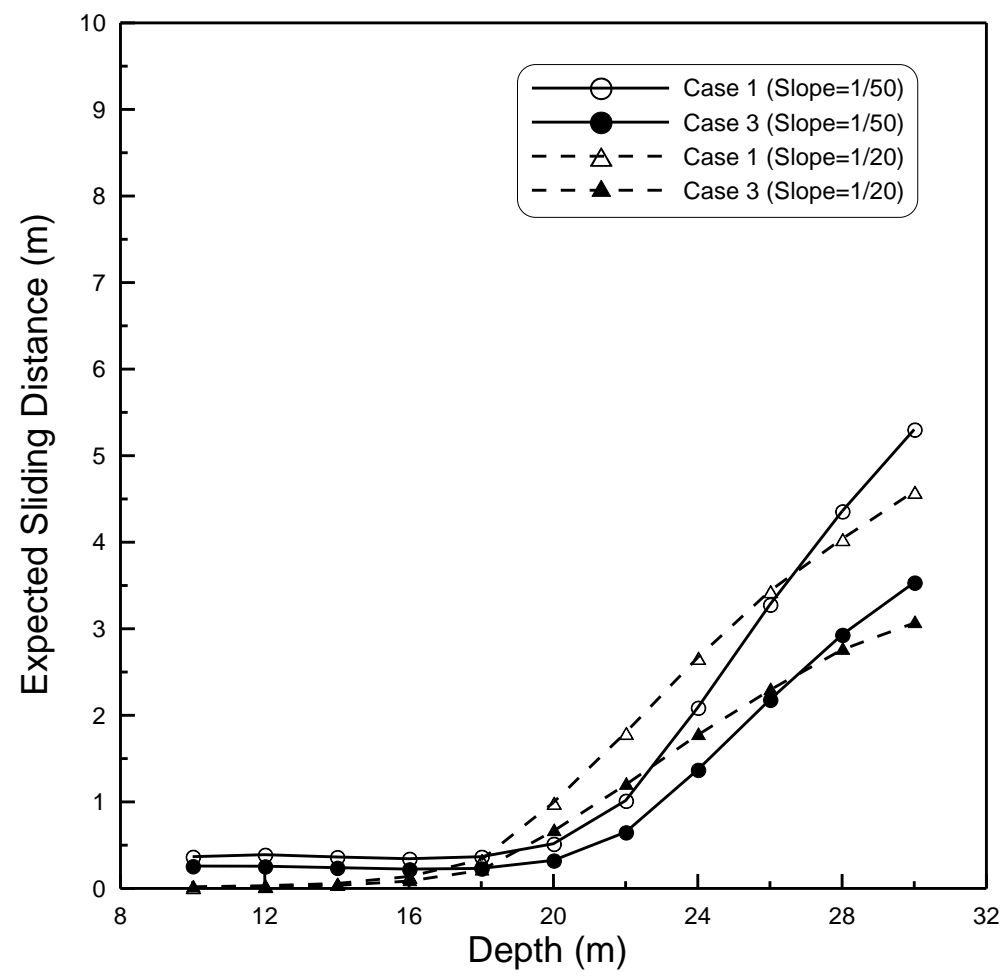

Figure 6. Change of expected sliding distance due to effect of wave refraction. 


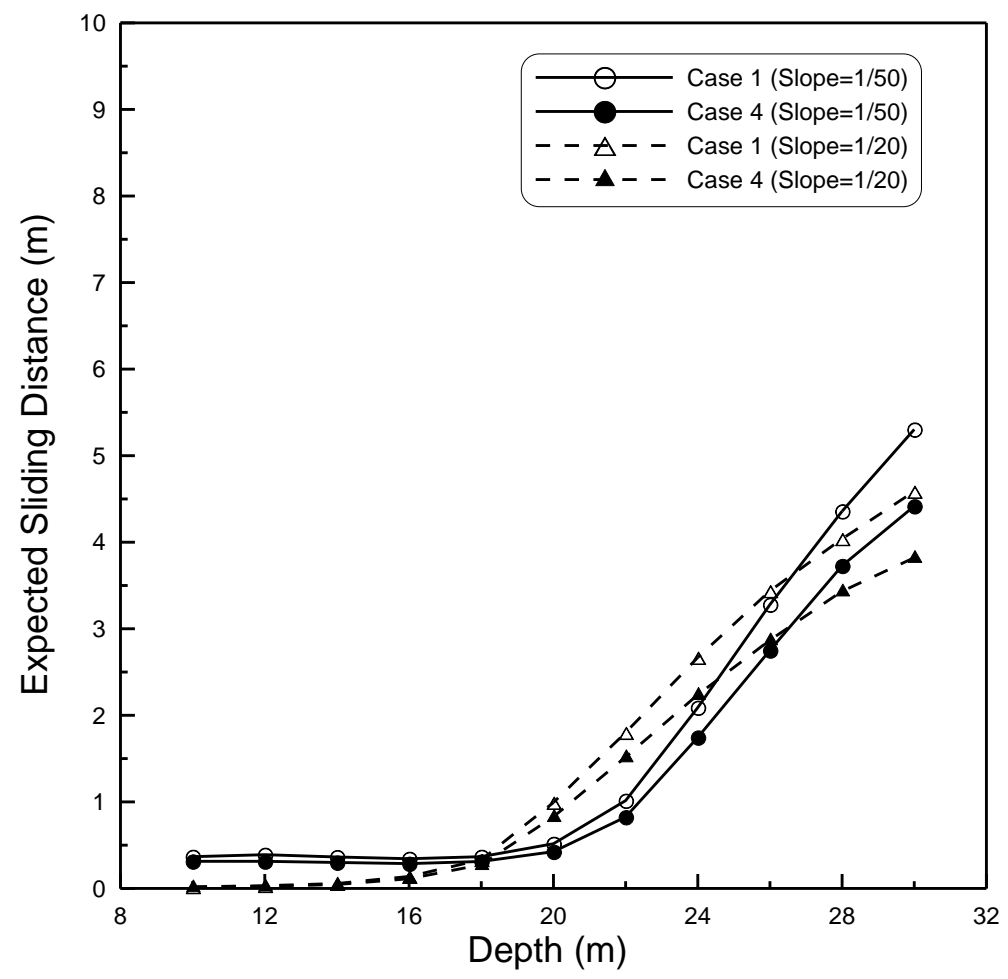

Figure 7. Change of expected sliding distance due to effect of variation of principal wave direction. 


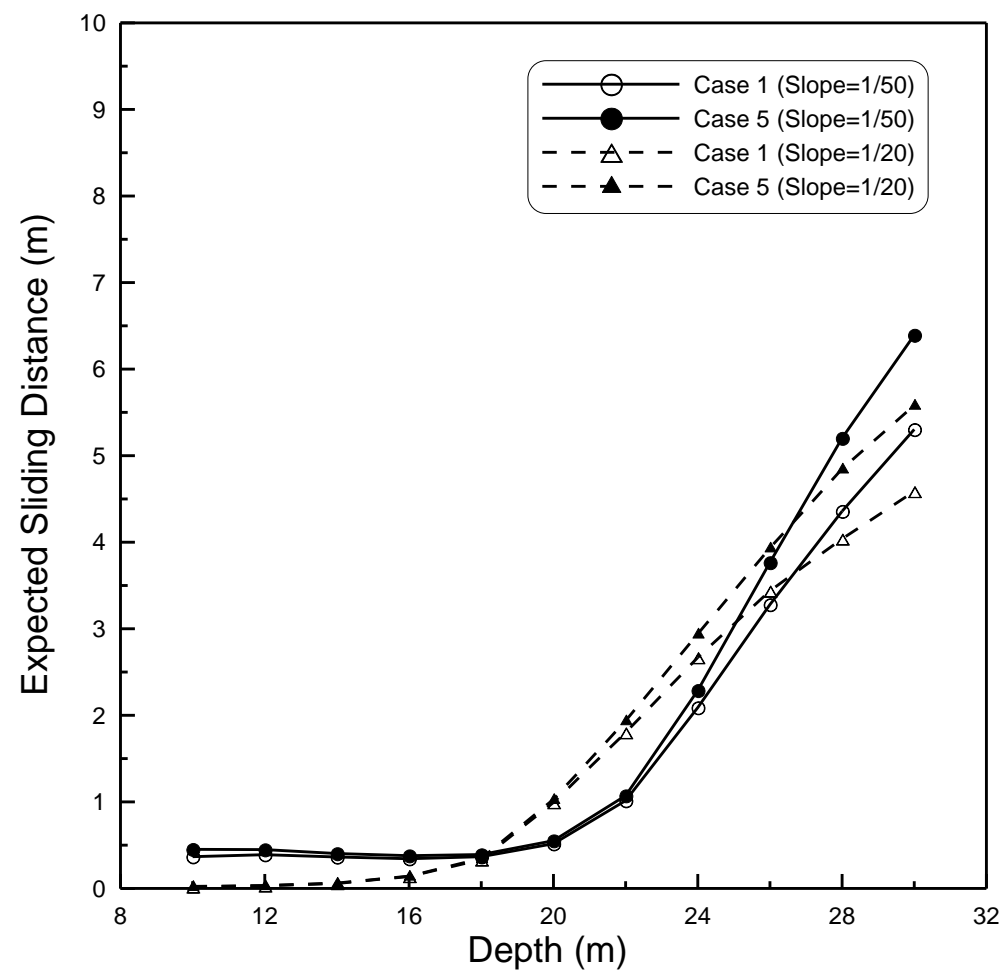

Figure 8. Change of expected sliding distance due to all effects of directional spreading, wave refraction, and variation of principal wave direction: $\left(\alpha_{p}\right)_{0 D}=10^{\circ}$. 


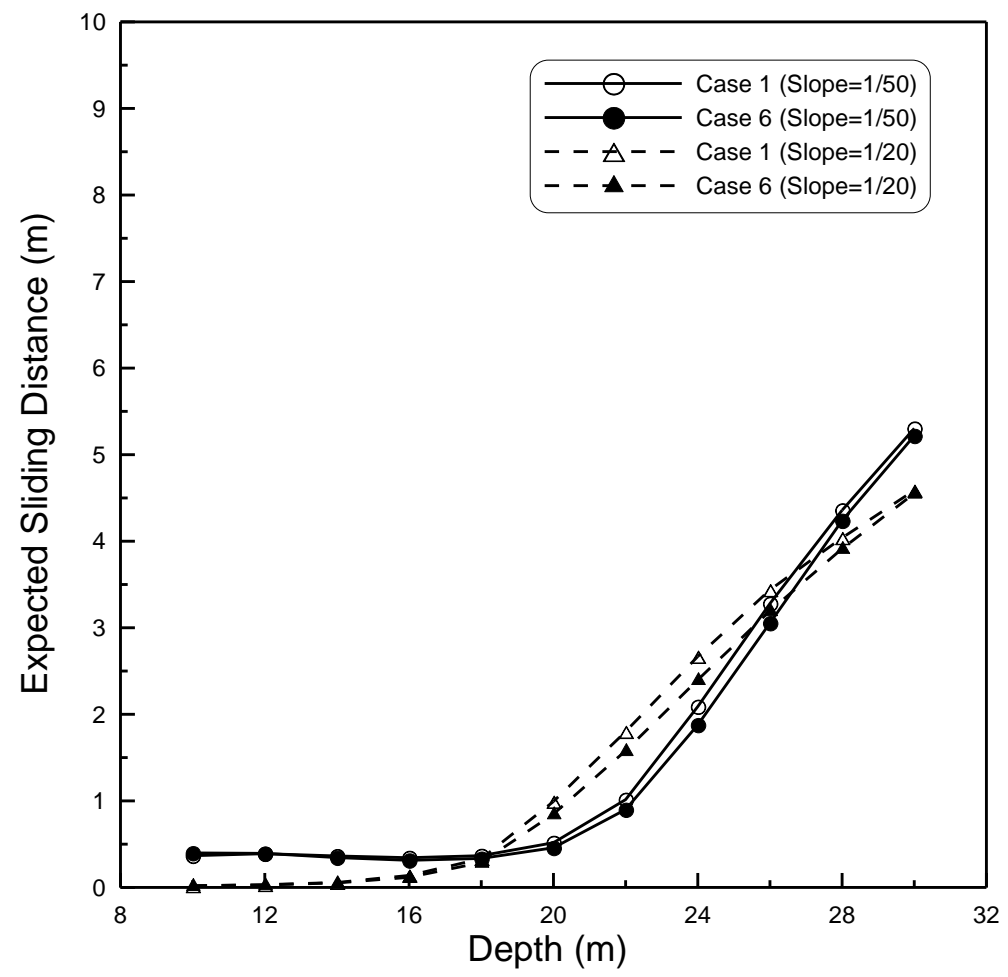

Figure 9. Same as Figure 8 but for $\left(\alpha_{p}\right)_{0 D}=20^{\circ}$. 


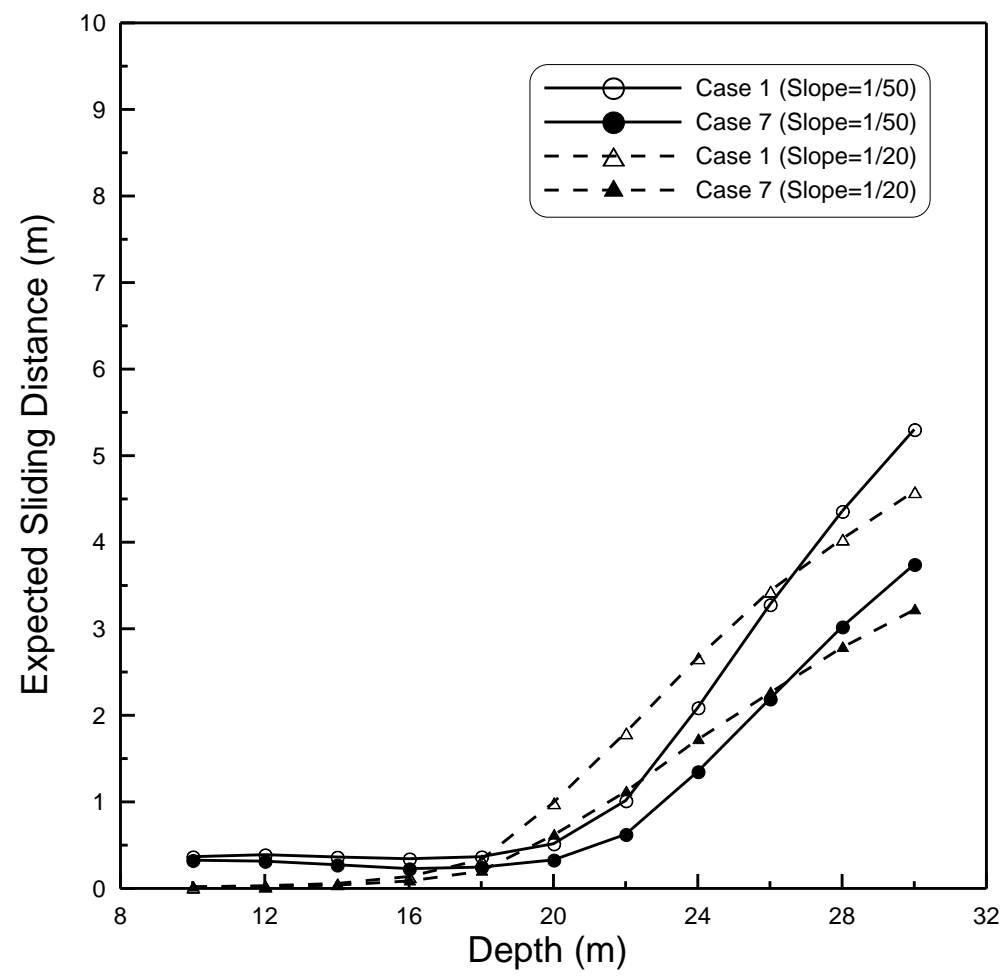

Figure 10. Same as Figure 8 but for $\left(\alpha_{p}\right)_{0 D}=30^{\circ}$. 


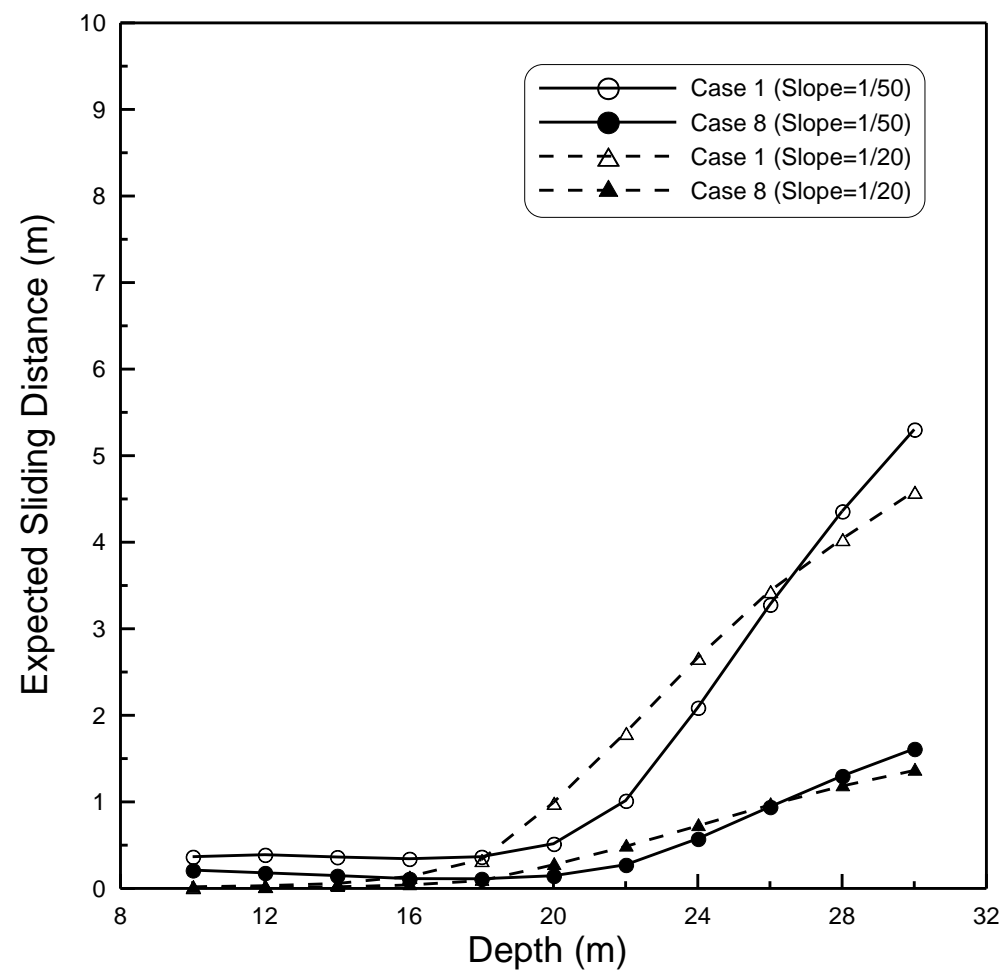

Figure 11. Same as Figure 8 but for use of field data between Uljin and Pohang in east coast of Korea. 


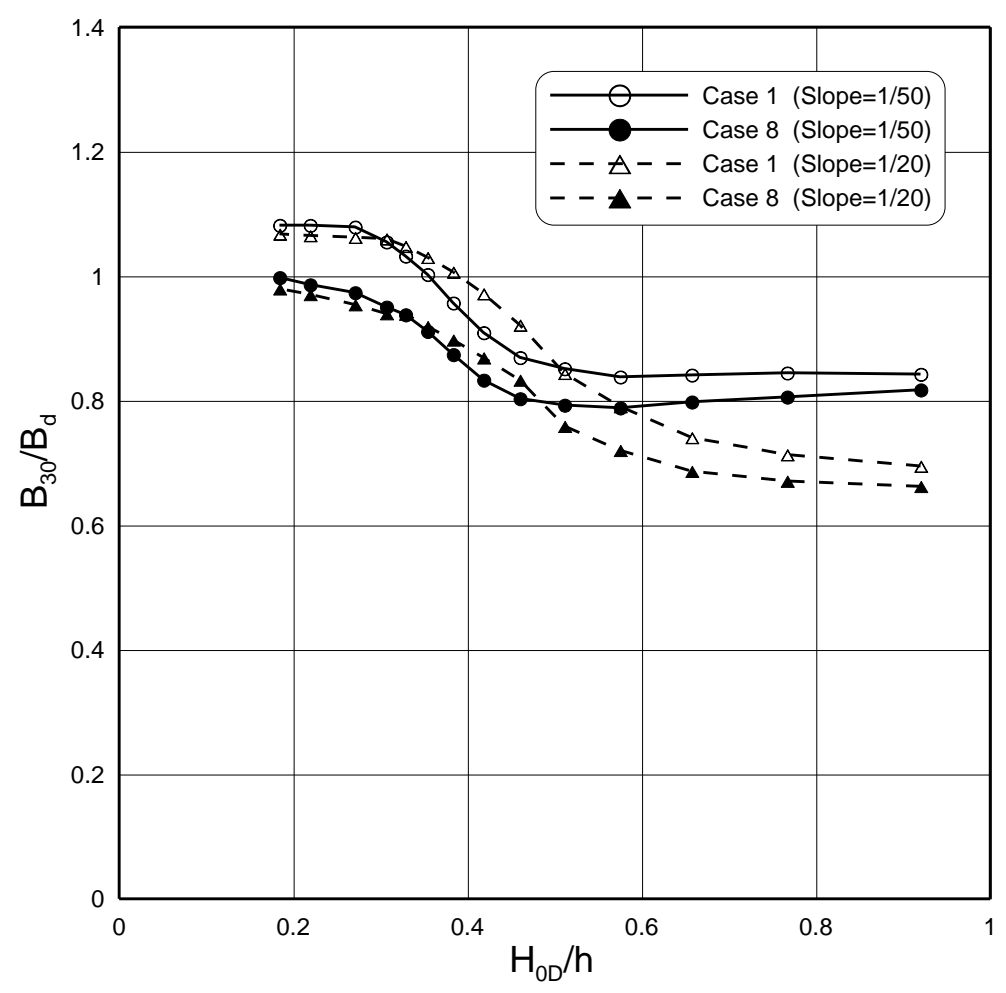

Figure 12. Comparison of relative caisson width as function of water depth between Case 1 and 8. 


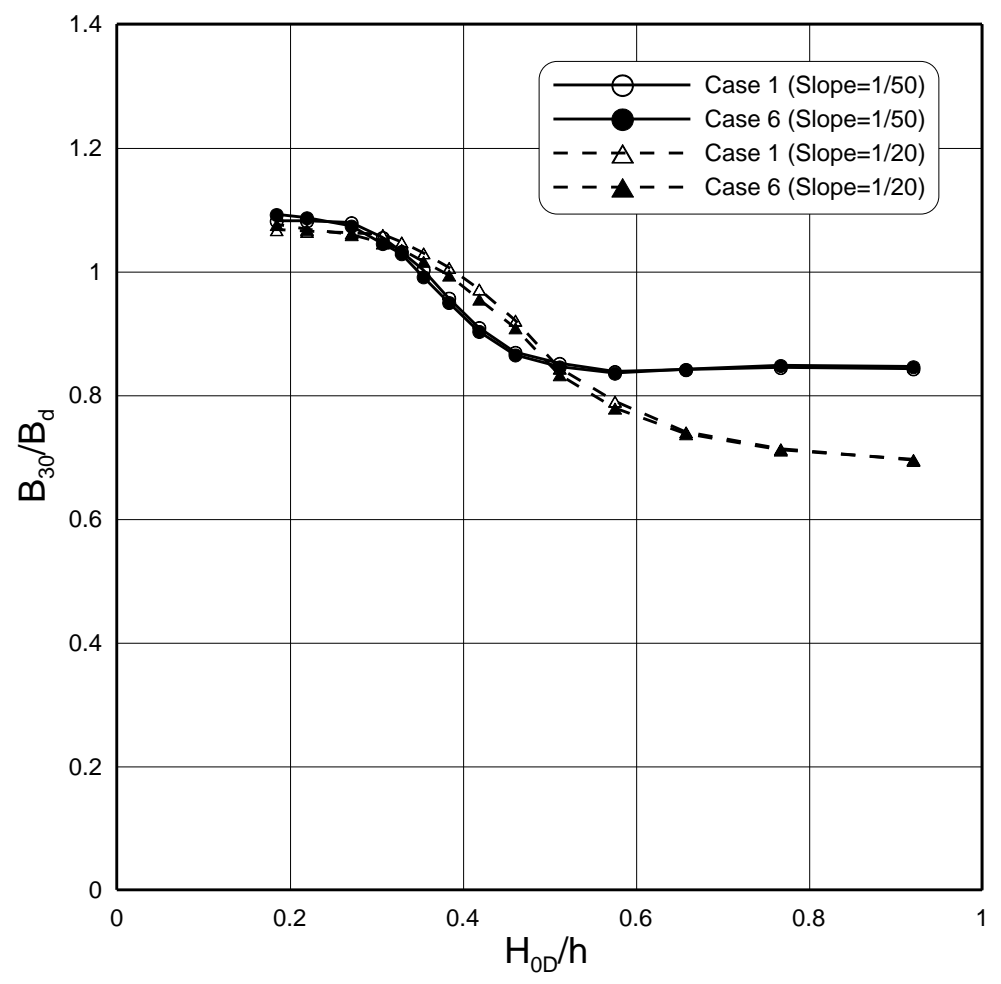

Figure 13. Same as Figure 12 but for between Case 1 and 6. 